\title{
Rumination Disorder
}

National Cancer Institute

\section{Source}

National Cancer Institute. Rumination Disorder. NCI Thesaurus. Code C92567.

An eating disorder most commonly observed in infants characterized by the repeated regurgitation and rechewing of food for a period of at least one month; this behavior is not associated with a gastrointestinal or other medical reason. 